19 Melton LJ, Ilstrup DM, Riggs BL, Beckenbaugh RD. Fifty-year trend in hip fracture incidence. Clin Orthop 1982;162:144-9.

${ }^{20}$ Horsman A, Nordin BEC, Aaron J, Marshall DH. Cortical and trabecular osteoporosis and their relation to fractures in the elderly. In: Deluca HF, Frost HM, Jee WSS, Johnston CC, Parfitt AM, eds. Osteoporosis. Baltimore: University Park Press, $1981: 175-84$

${ }^{21}$ Aitken JM, Smith CB, Horton PW, Clark DL, Boyd JF, Smith DA The interrelationships between bone mineral at different skeletal sites in male and female cadavera. F Bone foint Surg 1974;56B:370-5.

22 Nordin BEC. International patterns of osteoporosis. Clin Orthop 1966 45:17-30.

${ }^{23}$ Boston DA. Bilateral fractures of the femoral neck. Injury 1982;14: 207-10.
24 Sheldon JH. On the natural history of falls in old age. $\mathrm{Br}$ Med $\mathcal{F} 1960$;i : 1685-90.

${ }^{25}$ Exton-Smith AN. For people in their 60 s, fractures and falls are a special hazard. Modern Geriatrics 1976;July:27-30.

${ }^{26}$ Iskrant AP, Smith RW. Osteoporosis in women 45 years and over related to subsequent fractures. Public Health Rep 1969;84:33-8.

27 Solomon L. Osteoporosis and fracture of the femoral neck in the South African Bantu. F Bone foint Surg 1968;50B:2-13.

${ }^{28}$ Solomon L. Bone density in ageing Caucasian and African populations. Lancet 1979 ;ii:1326-30.

(Accepted 17 November 1983)

\title{
Effects of self poisoning with maprotiline
}

\author{
KAI KNUDSEN, ANDREW HEATH
}

\begin{abstract}
Self poisoning with maprotiline was studied in 41 patients (43 episodes) consecutively admitted to an intensive care unit. Thirty five patients had taken more than one drug or alcohol. Fifteen patients were in coma grade III or IV; 17 patients were still not conscious after 24 hours in the intensive care unit. Among six patients given ventilation the mean duration of ventilation in the five who recovered was 36 hours. Three patients had a cardiorespiratory arrest, and one patient died. Twenty eight patients had a QRS interval of $100 \mathrm{~ms}$ or more, and 15 patients had seizures. In six patients seizures were precipitated by physostigmine.

Cardiotoxicity after overdosage of maprotiline is equal to if not greater than that found after overdosage of conventional tricyclic antidepressants. Overdosage of maprotiline is more often associated with seizures than overdosage with tricyclic antidepressants. Physostigmine further increases the risk of seizures and should not be used in cases of overdosage of maprotiline.
\end{abstract}

\section{Introduction}

Self poisoning with antidepressant drugs is a common medical emergency requiring intensive care, although many patients die before admission to hospital. ${ }^{1}$ Because of the risk of self poisoning by patients with depression many new antidepressants have been marketed, each claiming fewer side effects and reduced acute toxic effects compared with the others. Maprotiline was one of the first commercially available tetracyclic antidepressants and was launched as a rapidly acting antidepressant with relatively few anticholinergic and cardiovascular side effects. ${ }^{2}$ Several case reports have recently been published of grand mal seizures during treatment with $^{3-9}$ and after overdose of ${ }^{10-11}$ maprotiline in patients not known to be epileptics. Seizures are known to be

\footnotetext{
Poisons Therapy Group, Department of Anaesthesia and Intensive Care, Sahlgren's Hospital, University of Gothenburg, S-413 45 Gothenburg, Sweden

KAI KNUDSEN, MD, senior house officer

ANDREW HEATH, MD, PHD, consultant

Correspondence to: Dr Andrew Heath.
}

a complication of overdosage of tricyclic antidepressants. ${ }^{12} \mathrm{We}$ carried out a study to assess the effects of self poisoning with maprotiline with particular reference to seizures.

\section{Patients and methods}

Forty one patients with overdosage of maprotiline consecutively admitted to the intensive care units at Sahlgren's and East hospitals, Gothenburg, from January 1978 to May 1983 were included in the study. The diagnosis of overdosage of maprotiline was confirmed by the patient on recovery or by quantitative or qualitative toxicological analysis, or both. Coma grade was assessed using the scale of Matthew and Lawson, ${ }^{13}$ the most severe grade being recorded for each patient (grade 0 , fully conscious; grade I, drowsy but obeys commands; grade II, unresponsive to commands but responds well to pain; grade III, unresponsive to commands and minimally responsive to pain; grade IV, completely unresponsive). Hypotension was defined as a systolic blood pressure $<90 \mathrm{~mm} \mathrm{Hg}$. Statistical analysis was made using the $\chi^{2}$ test.

\section{Results}

Patients and drugs-The 41 patients were treated for 43 episodes of overdosage with maprotiline. The mean age of the patients was 34 (SD 11.2) years (range 20-66 years); overdosage was most common among patients aged $20-40$. The 41 patients comprised 27 women and 14 men. Six patients had taken maprotiline alone; the remaining 35 patients had taken more than one drug (maprotiline plus a benzodiazepine, 18 patients; maprotiline plus alcohol, nine; maprotiline plus a tricyclic antidepressant, one; maprotiline plus a tricyclic antidepressant and alcohol, four; maprotiline plus a tricyclic antidepressant and a benzodiazepine, one; and maprotiline plus other drugs, four). The amount of maprotiline ingested could be estimated in 35 patients. The average ingested dose was $2.31(1.47) \mathrm{g}$; five patients had taken more than $4 \mathrm{~g}$ and one patient more than $7 \mathrm{~g}$.

Coma-The table shows the depth of coma as assessed with the Matthew-Lawson coma scale. Twenty four hours after admission 17 of the patients were still comatose; seven patients were still comatose after 48 hours and three patients after 72 hours.

Respiratory depression-An endotracheal tube was passed in nine of the 43 episodes. Six patients required assisted ventilation. Of these six, one received ventilation for 23 days because of brain damage after cardiac arrest. The five other patients, whose clinical course was not complicated, received ventilation for a mean of 36 hours.

Cardiovascular reactions-Eighteen patients were admitted with a heart rate of 100 beats/min or more. Characteristic electrocardiographic changes were first degree atrioventricular block (11 patients) and an increased QRS interval ( $\geqslant 100 \mathrm{~ms}, 28$ patients; $\geqslant 120 \mathrm{~ms}$, 
18 patients). The increase in QRS interval was also associated with a lower level of consciousness (table). Arrhythmias such as supraventricular or ventricular arrhythmias were seen in nine patients. In one patient a complete left bundle branch block, not present before the overdose, remained after discharge from hospital. Other electrocardiographic sequelae such as $T$ wave abnormalities or a $Q$ wave remained on discharge in a further three patients. Hypotension (systolic pressure $\leqslant 90 \mathrm{~mm} \mathrm{Hg}$ ) was observed in eight patients. Cardiac arrest occurred soon after admission in three patients: all three were successfully resuscitated, although one died after 23 days. The two other patients made an uneventful recovery and were discharged from the intensive care unit after three days. A characteristic feature in these three cases of extremely severe overdosage was a progressive widening of the QRS interval and bradycardia preceding asystole.

Numbers of episodes in which seizures developed or with a $Q R S$ interval $\geqslant 100 \mathrm{~ms}$ according to coma grade

\begin{tabular}{cccc}
\hline Coma grade & $\begin{array}{c}\text { No of } \\
\text { patients }\end{array}$ & $\begin{array}{c}\text { No (\%) with } \\
\text { seizures }\end{array}$ & $\begin{array}{c}\text { No }(\%) \text { with } \\
\text { QR interval } \\
\geqslant 100 \mathrm{~ms}\end{array}$ \\
\hline II & 0 & 0 & 0 \\
II & 8 & $3(37 \cdot 5)$ & $4(50)$ \\
III & 20 & $6(30)$ & $10(50)$ \\
IV & 6 & $2(33 \cdot 3)$ & $5(83 \cdot 3)$ \\
\hline Total & 9 & $4(44 \cdot 4)$ & $9(100)$ \\
\hline
\end{tabular}

Seizures-Fifteen patients had seizures. Fourteen had typical grand mal convulsions, which occurred within the first 24 hours after admission. These convulsions did not always respond to diazepam; in two cases phenytoin was used. Seizures occurred in $13(46 \%)$ of the 28 episodes with a $\mathrm{QRS}$ interval $\geqslant 100 \mathrm{~ms}$ compared with only two of the 15 episodes $(13.3 \%)$ with a QRS interval $<100 \mathrm{~ms}$. There did not appear to be any relation between the grade of coma and seizures (table). Seven patients were given physostigmine as an antidote. Six of these seven developed seizures; in five cases the seizures developed after the administration of physostigmine. The one patient given physostigmine who did not develop convulsions had also taken a benzodiazepine. Patients who had taken an overdosage of maprotiline with a benzodiazepine had a significantly lower incidence of seizures (four out of 19 patients $(21 \%)$ ) than other patients (11 out of 24 $(46 \%))(\mathrm{p}<0.05)$.

Other complications-An aspiration syndrome was seen in four patients. Three patients had hallucinations during recovery. One patient had delirium tremens necessitating prolonged intensive care.

\section{Discussion}

Self poisoning with maprotiline shows a similar epidemiological pattern to self poisoning with tricyclic antidepressants, with similar age and sex distributions. ${ }^{14}$ Multiple drug overdose was common in this study, a benzodiazepine and alcohol being the other drugs most commonly taken. As our patients were similar to an unselected group of patients who had taken overdoses of tricyclic antidepressants ${ }^{14}$ some comparisons may be made between these studies. Depth of coma after overdosage of maprotiline appeared to be similar to that seen after overdosage of amitriptyline. The duration of coma, however, was longer with maprotiline: almost $40 \%$ of patients remained comatose after 24 hours, compared with $9 \%$ of patients after overdosage of amitriptyline. ${ }^{14}$ Similarly, our patients who required assisted ventilation received it for longer periods than patients after overdosage of amitriptyline. These differences can be explained by the longer elimination half life of maprotiline, which is reported to be 43 hours, ${ }^{15}$ compared with the elimination half life of amitriptyline in the $\beta$ phase after overdose of about 22 hours. ${ }^{16}$ The proportion of our patients who required assisted ventilation was similar to that requiring ventilation after overdosage of tricyclic antidepressants. ${ }^{14}$

In therapeutic doses maprotiline reportedly shows less cardiotoxicity than conventional tricyclic drugs ${ }^{17}$ and has a low arrhythmogenic potential. ${ }^{18}$ These findings were not confirmed in the present study of maprotiline in overdose. An increased
QRS interval was seen twice as often in this study as after overdosage of tricyclic antidepressants necessitating intensive care. ${ }^{14}$ As an increased QRS interval is associated with increased morbidity and mortality ${ }^{12}$ it is a useful prognostic tool. Other electrocardiographic changes seen in our patients were the same as those seen after overdosage of tricyclic antidepressants, characterised by pronounced bradycardia immediately preceding asystole. Asystole has previously been reported after treatment with physostigmine for overdosage of amitriptyline and imipramine. $^{19}$ None of our three patients with cardiac arrest, however, had been treated with physostigmine.

Seizures induced by maprotiline can occur both at therapeutic doses and in overdose. ${ }^{3-11}$ In 1979 the Committee on the Safety of Medicines reported that $42 \%$ of all reported drug induced convulsions were caused by maprotiline, with all other antidepressants responsible for $28 \%{ }^{6}{ }^{60}$ These findings have been questioned, as maprotiline has been reported to be less epileptogenic than conventional tricyclic antidepressants. ${ }^{21}{ }^{22}$ Holliday et al recently suggested that seizures may be more common at doses greater than $150 \mathrm{mg} /$ day. So far, however, the incidence of seizures induced by maprotiline has not been established. In this study one third of the patients developed seizures. This contrasts sharply with a group of 225 patients treated in an intensive care unit after overdosage of tricyclic antidepressants, of whom $8 \%$ developed convulsions. ${ }^{14}$ Six of our seven patients given physostigmine had seizures. Physostigmine clearly induces seizures if used to treat overdosage of maprotiline: any short term gain with physostigmine such as a temporary increase in consciousness is outweighed by the risk of convulsions or asystole. At least in overdosage of maprotiline (and probably also in overdosage of tricyclic antidepressants) physostigmine is a dangerous drug and its use should be abandoned. Nevertheless, physostigmine alone is not responsible for the greater incidence of seizures after overdosage of maprotiline than after overdosage of tricyclic antidepressants. When our patients treated with physostigmine were excluded the incidence of seizures was still more than twice that after overdosage of tricyclic antidepressants.

Treatment after overdosage of maprotiline, as after overdosage of tricyclic antidepressants, should be based on careful supportive care. Dialysis and haemoperfusion are not effective because of maprotiline's long half life and large volume of distribution. ${ }^{16}$ The longer half life also results in a longer period of coma and a longer period of ventilation. The cardiotoxicity of maprotiline in overdose is equal to, if not greater than, that of conventional tricyclic antidepressants, and hence electrocardiography is useful in assessing the severity of the overdosage.

\section{References}

${ }^{1}$ Crome P, Newman B. Fatal tricyclic antidepressant poisoning. $\mathcal{F}$ Soc Med 1979;72:649-53.

2 Ananth J, Ayd FJ. Maprotiline therapy. In: Ayd FJ, ed. Clinical depression. Update. Diagnostic and therapeutic challenges. Baltimore: Ayd Medical Communications, 1980:77-89.

${ }^{3}$ Daneel AB, Leigh W. Side effects of maprotiline. $S$ Afr Med $\mathcal{F} 1974$;48: 2009.

- Hall MJ, Russell RI. Maprotiline hydrochloride and grand mal seizures. Br Med f 1978;ii:961.

${ }^{5}$ Marais GFT. Clinical evaluation of the antidepressants: maprotiline and amitriptyline. $S$ Afr Med $\mathcal{F} 1974 ; 48: 1530-2$.

${ }^{6}$ Shepherd GA, Kerr F. Maprotiline hydrochloride and grand mal seizures. Br Med f 1978;i:1523.

7 Holliday W, Brasfield KH, Powers B. Grand mal seizures induced by maprotiline. Am f Psychiatry 1982;139:673-4.

* Scwartz L, Swaminathan S. Maprotiline hydrochloride and convulsions: a case report. Am $\mathcal{F}$ Psychiatry 1982;139:244-5.

9 Hoffman BF, Wachsmuth R. Maprotiline and seizures. $\mathcal{f}$ Clin Psychiatry $1982 ; 43: 117-8$

10 Crome P, Newman B. Poisoning with maprotiline and mianserin. Br Med f 1977 ;ii :260.

1 Park J, Proudfoot AT. Acute poisoning with maprotiline hydrochloride. Br Med F 1977; i:1573.

12 Petit JM, Spiker DJ, Ruwitch JF, Ziegler VE, Weiss AN, Biggs JT. Tricyclic antidepressant plasma levels and adverse effects after overdose. Clin Pharmacol Ther 1977;21:47-51. 
${ }^{13}$ Matthew H, Lawson AAH. Acute barbiturate poisoning-a review of two years experience. $Q \mathcal{F}$ Med 1966;35:539-52.

14 Hultén BA, Heath A. Clinical aspects of tricyclic antidepressant poisoning Acta Med Scand 1983;213:275-8.

15 Grüter A, Pöldinger B. Maprotiline. Mod Probl Pharmacopsychiatry 1982; 18:17-48.

16 Heath A, Wickström I, Ahlmén J, Màrtensson E. Treatment of antidepressant poisoning with resin haemoperfusion. Human Toxicology $1982 ; 1: 361-71$.

${ }^{17}$ Brorson L, Wennerblom B. Effect of the tetracyclic antidepressant maprotiline on cardiac electrophysiology in human volunteers. $\mathcal{F}$ Cardiovasc Pharmacol 1982;4:531-5.
18 Bethge K-P, Godt U, Blanco-Cruz E, Lichtlen PR. Incidence of cardiac arrhythmias during antidepresisant therapy with maprotiline or nomifensine. 7 Cardiovasc Pharmacol 1982;4:142-8.

19 Pentel P, Peterson CD. Asystole complicating physostigmine treatment of tricyclic antidepressant overdose. Ann Emerg Med 1980;9:588-90.

20 Edwards JG. Antidepressants and convulsions. Lancet 1979;ii:1368-9.

21 Ayd FJ. Maprotiline: an effective tetracyclic antidepressant. International Drug Therapy Newsletter 1973;8:17-24.

22 Trimble $M$. Non monoamine oxidase inhibitor antidepressants and epilepsy: a review. Epilepsia 1978;19:241-50.

(Accepted 15 November 1983)

\title{
Effects of mild physical exercise on serum lipoproteins and metabolites of arachidonic acid: a controlled randomised trial in middle aged men
}

\author{
RAINER RAURAMAA, JUKKA T SALONEN, KATRIINA KUKKONEN-HARJULA, KARI SEPPÄNEN, \\ ERKKI SEPPĂLA,, HEIKKI VAPAATALO, JUSSI K HUTTUNEN
}

\begin{abstract}
To study the effects of physical exercise on biochemical risk factors for ischaemic heart disease 31 healthy middle aged men undertook regular physical exercise for two months and 29 served as controls in a randomised trial. In the men taking regular exercise serum cholesterol concentrations increased $26 \%$ more. in the high density lipoprotein subfraction two $\left(\mathrm{HDL}_{2}\right)$ and decreased $31 \%$ more in the subfraction three $\left(\mathrm{HDL}_{3}\right)$ and $9 \%$ more in the low density lipoprotein fraction than in the control group. A tendency towards increased plasma 6-ketoprostaglandin $F_{1 \alpha}$ concentration and decreased serum thromboxane $B_{2}$ concentration was found during the period of regular exercise, but prostaglandin $E_{2}$ concentrations remained unchanged. The increase in plasma 6-keto-prostaglandin $F_{1 \alpha}$ concentration was associated with an increase in serum $\mathrm{HDL}_{2}$ cholesterol concentration in the group taking regular exercise.

Our data suggest that mild regular physical exercise favourably influences cholesterol distribution in serum lipoproteins in healthy middle aged men and may have beneficial effects on circulating metabolites of asachidonic acid.
\end{abstract}

\footnotetext{
Kuopio Research Institute of Exercise Medicine, Puistokatu 20, SF-70100, Kuopio 10, Finland

RAINER RAURAMAA, MD, director

KARI SEPPÄNEN, BSC, researcher

Research Institute of Public Health, University of Kuopio, Kuopio, Finland

JUKKA T SALONEN, MD, director, professor
}

Kuopio Regional Institute of Occupational Health, Kuopio, Finland KATRIINA KUKKONEN-HARJULA, MD, physician

Department of Biomedical Sciences, University of Tampere, Tampere, Finland

ERKKI SEPPÄLÄ, MD, researcher

HEIKKI VAPAATALO, MD, professor

National Public Health Institute, Helsinki, Finland JUSSI K HUTTUNEN, MD, director, professor

Correspondence to: Dr R Rauramaa.

\section{Introduction}

The relation of decreased serum high density lipoprotein cholesterol concentration and increased low density lipoprotein cholesterol concentration to ischaemic heart disease has been established epidemiologically. ${ }^{1}$ Evidence suggests that it is the high density lipoprotein subfraction two $\left(\mathrm{HDL}_{2}\right)$ that protects against ischaemic heart disease. ${ }^{2}$ Advanced atherosclerosis in man is also characterised by decreased production of prostacyclin in the vascular endothelium ${ }^{3}$ and increased production of thromboxane $\mathrm{A}_{2}$ by the platelets. ${ }^{4}$ It has been suggested that regular physical activity prevents ischaemic heart disease, ${ }^{5}{ }^{6}$ but the mechanisms are only partly known. The most convincing evidence for this effect of regular exercise is the increase in serum high density lipoprotein cholesterol concentrations ${ }^{78}$; suggestions concerning the effects of exercise on high concentrations of low density lipoprotein cholesterol as well as on the antiaggregatory and proaggregatory metabolites of arachidonic acid-namely, prostacyclin and thromboxane-have been based on uncontrolled findings alone. We studied the effects of mild regular physical exercise on circulating lipoproteins and metabolites of arachidonic acid in healthy middle aged men in a controlled randomised clinical trial.

\section{Subjects and methods}

We recruited the subjects from a group of 82 clinically healthy male volunteers aged 32-44 who were contacted through an advertisement in a local newspaper and on the radio. The design of the study was explained to them, and they gave their spoken consent. They then underwent medical examination, chest $x$ ray examination, exercise testing, and laboratory examinations. Twenty two men were excluded because they were overweight (body mass index (weight $\left./(\text { height })^{2}\right)>$ $\left.27 \mathrm{~kg} / \mathrm{m}^{2}\right)$, had a high maximal oxygen consumption $(>55 \mathrm{ml} / \mathrm{kg} \times$ min), or had hypercholesterolaemia (serum cholesterol concentration $>7.5 \mathrm{mmol} / 1(290 \mathrm{mg} / 100 \mathrm{ml})$ ) or hypertriglyceridaemia (serum triglyceride concentration $>2.0 \mathrm{mmol} / \mathrm{l}(175 \mathrm{mg} / 100 \mathrm{ml})$ ). The mean (SD) age of the 60 men included in the study was 37 (2). They were all non-manual workers. The men were asked to keep their dietary and other living habits constant during the study.

After a lead in period of one month baseline laboratory tests were carried out. Blood samples for determining concentrations of lipoprotein and arachidonic acid metabolite were taken, after a 10 hour fast, from 0800 to 1000 with the subjects in a sitting position. The first $2 \mathrm{ml}$ of blood obtaised after the venous puncture was discarded; the sample for testing was then taken without a tourniquet. The men were advised not to drink alcohol or take physical exercise in their free 